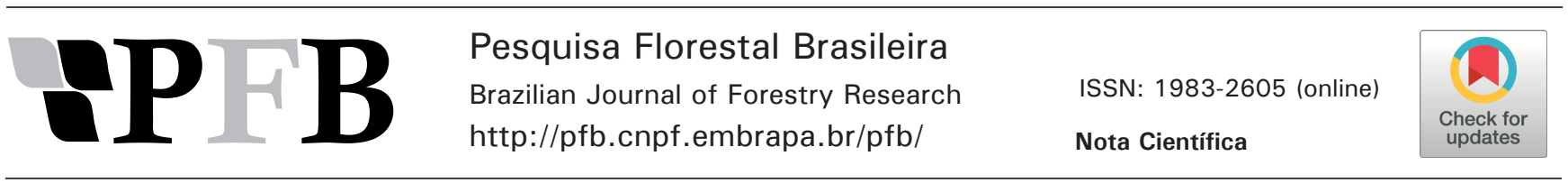

\title{
Influência de tratamentos pré-germinativos e crescimento inicial de plântulas de Libidibia ferrea
}

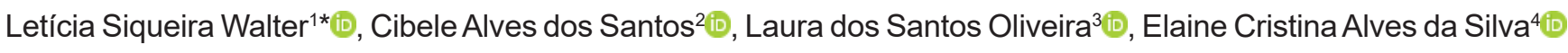 \\ ${ }^{1}$ Universidade Federal do Paraná, Av. Pref. Lothário Meissner, 632, Jardim. Botânico, CEP 80210-170, Curitiba, PR, Brasil \\ ${ }^{2}$ Centro Universitário Brasileiro, R. Padre Inglês, 25, Boa Vista, CEP 50050-230, Recife, PE, Brasil \\ ${ }^{3}$ Secretaria de Planejamento, Meio Ambiente e Orçamento Participativo de Camaragibe, Av. Belmiro Correia, 3038, Timbi, CEP 54768-000, Camaragibe, PE, Brasil \\ ${ }^{4}$ Universidade Federal Rural do Semi-Árido, Av. Francisco Mota, 572, Bairro Costa e Silva, CEP 59.625-900, Mossoró, RN, Brasil
}

\author{
"Autor correspondente: \\ leticiasiqueira.walter@gmail.com \\ Termos para indexação: \\ Germinação \\ Produção de mudas \\ Dormência \\ Index terms: \\ Germination \\ Seedlings production \\ Dormancy \\ Histórico do artigo: \\ Recebido em 07/08/18 \\ Aprovado em 20/11/18 \\ Publicado em 29/12/18 \\ $\underline{\text { doi: } 10.4336 / 2018 . p f b .38 \mathrm{e} 201801684}$
}

\begin{abstract}
Resumo - Objetivou-se verificar a influência de tratamentos pré-germinativos no vigor de germinação e crescimento inicial de mudas de Libidibia ferrea. Foram utilizados 5 tratamentos: controle; ácido sulfúrico; água por 24 h; água quente e escarificação. Para a germinação, avaliou-se a porcentagem $(\% \mathrm{E})$, o índice de velocidade (IVE) e o tempo médio de emergência (TME) e para o crescimento inicial, avaliou-se a altura das mudas, diâmetro do caule, número de folhas, matéria seca das folhas, caule e das raízes, e razão raiz/parte aérea. O tratamento com ácido sulfúrico resultou em maior $\%$ E IVE e menor TME, apresentando, também, o melhor crescimento das plantas.
\end{abstract}

\section{Influence of pre-germination treatments on initial growth of Libidibia ferrea seedlings}

\begin{abstract}
The aim of this research was to evaluate the influence of pre-germination treatments on germination and initial seedling growth of Libidibia ferrea. We tested 5 treatments: control; sulfuric acid; water for $24 \mathrm{~h}$; hot water and scarification. We evaluated the percentage of initial growth $(\% \mathrm{E})$, speed index (IVE) and mean emergence time (TME). For germination we evaluated the height and stem diameter of the seedlings, number of leaves, leaves, stem and roots dry matter and root/shoot ratio. Sulfuric acid treatment presented higher $\% \mathrm{E}$ and IVE and lower TME, and it was the treatment that showed the better growth of the plants.
\end{abstract}

Libidibia ferrea (Mart. ex. Tul.) L.P. Queiroz, tem como sinônimo Caesalpinia ferrea, e é popularmente conhecida como pau-ferro ou jucá, pertence na Família Fabaceae-Caesalpionoideae. Ocorre na região Nordeste, do Ceará até a Bahia,na Caatinga arbórea e arbustiva, e no Sudeste, na Floresta Pluvial Atlântica. Esta espécie apresenta grande valor econômico, com praticamente todas as partes da árvore podendo ser utilizadas para diversas finalidades. Por manter suas folhas durante a época de estiagem, essas são utilizadas como forragem para ovinos e caprinos. As cascas, raízes e frutos apresentam substâncias com propriedades medicinais, que são utilizadas pela população da região (Lorenzi, 1992; Câmara et al., 2008; Silva et al., 2011; Lima, 2012; Maia, 2012).

Sabe-se que em espécies florestais é corriqueira a ocorrência de dormência nas sementes em um grande número de espécies. Porém, quando em seu local de ocorrência, a dormência torna-se um mecanismo de sobrevivência e de perpetuação da espécie, evitando 
que as sementes germinem todas ao mesmo tempo e que formem populações aglomeradas (Carvalho \& Nakagawa, 2000; Santana et al., 2011). Para que ocorra a germinação, é necessário que haja a reidratação do embrião, quando a semente está madura, reiniciando os processos metabólicos, para o embrião se desenvolver (Taiz et al., 2017). L. ferrea apresenta dormência mecânica, que na natureza pode ser quebrada quando passa pelo trato intestinal de ruminantes. O tegumento é impermeável e duro, o que dificulta a absorção de água, fazendo com que sua germinação seja desuniforme. Portanto, quando tem-se por objetivo a produção de mudas, faz-se necessária a utilização de tratamentos para superar a dormência e obter germinação uniforme (Lorenzi, 1992; Galdino et al., 2007; Santana et al., 2011; Maia, 2012).

O estágio de plântula é a fase mais crítica. Nesta fase as plantas estão mais susceptíveis ao ataque de patógenos, pois apresentam paredes celulares finas e, também, o caule ainda não está lignificado o suficiente para dificultar a entrada de patógenos. Segundo Taiz et al. (2017), crescimento é definido como o aumento irreversível do volume, podendo ser determinado através do peso seco das plantas em um determinado período. Pela análise do crescimento, é possível conhecer as diferenças funcionais e estruturais entre variedades de uma mesma espécie, as adaptações da planta em diferentes condições ambientais, ou mesmo conhecêla para trabalhos futuros de melhoramento genético (Benincasa, 2003).

Diante do exposto, a presente pesquisa teve como objetivo avaliar a influência de tratamentos de superação de dormência das sementes no vigor de germinação e no crescimento inicial de mudas de Libidibia ferrea.

O experimento foi conduzido no Laboratório de Fisiologia Vegetal, da Universidade Federal Rural de Pernambuco entre março e julho de 2017. Os frutos foram coletados em árvores da Estação Experimental de Pequenos Animais do Carpina ( $7^{\circ} 50^{\prime} 20^{\prime \prime} \mathrm{S}$ e $35^{\circ} 15^{\prime} 20^{\prime}$ W, altitude de $183 \mathrm{~m}$ ), em agosto de 2016, e foram beneficiados com o auxílio de um martelo e um alicate. Na sequência, as sementes foram armazenadas em câmara fria, durante 6 meses, até a instalação do experimento.

O delineamento experimental utilizado foi inteiramente casualizado, com 5 tratamentos, sendo eles: controle sem aplicação de tratamento; ácido sulfúrico - as sementes foram imersas em ácido sulfúrico P.A. durante
15 min, e em seguida foram lavadas com água corrente, para retirar os resíduos do reagente; água, por 24 h; água quente - imersão das sementes em água a $100{ }^{\circ} \mathrm{C}$ até o resfriamento completo da água; e escarificação - as sementes foram lixadas, com lixa de madeira $n^{\circ} 100$, do lado oposto ao hilo. Cada tratamento contou com 4 repetições de 25 sementes cada.

As sementes foram postas para germinar em caixas gerbox, com substrato 3:1:1 - composto por 3 partes de material argiloso (barro vermelho), 1 parte de esterco curtido e 1 parte de cama de gado - proveniente do viveiro do Instituto Agronômico de Pernambuco (IPA). Foram contabilizadas diariamente, durante 22 dias, sendo consideradas germinadas as sementes com emergência do hipocótilo. Durante o período de avaliação da germinação, a temperatura interna da casa de vegetação apresentou média de $31,8{ }^{\circ} \mathrm{C}$ e umidade relativa do ar de $55 \%$.

Nesta etapa, foram avaliados a porcentagem $(\% \mathrm{E})$, o índice de velocidade (IVE), seguindo a metodologia descrita por Maguire (1962), e o tempo médio de emergência (TME) seguindo Labouriau (1983).

Após o término do experimento de germinação, foram selecionadas 10 plântulas de cada tratamento, de acordo com a uniformidade e sanidade. Essas foram transplantadas para embalagens plásticas de polietileno com dimensões de $17 \mathrm{~cm} \mathrm{x} 12 \mathrm{~cm}$, com o mesmo substrato utilizado na germinação. $O$ delineamento utilizado para a avaliação do crescimento inicial foi inteiramente casualizado, com 10 mudas por tratamento, totalizando 50 mudas. Foram mensuradas semanalmente, durante 90 dias, a altura das plântulas, com o auxílio de uma trena, o diâmetro, com um paquímetro digital, e a contagem do número de folhas.

Durante a avaliação de crescimento inicial, a temperatura média na casa de vegetação era $32,7{ }^{\circ} \mathrm{C}$ e a umidade relativa do ar, $61 \%$. Ao final do período experimental, as mudas foram retiradas do substrato, e separadas nos compartimentos folhas, caule e raízes. Cada parte foi acondicionada em sacos de papel e secas em estufa a $65^{\circ} \mathrm{C}$ para obtenção dos dados da matéria seca das folhas (MSF), matéria seca do caule (MSC) e matéria seca das raízes (MSR), sendo calculada a razão raízes/parte aérea $(\mathrm{R} / \mathrm{Pa})$, seguindo a metodologia proposta por Benincasa (2003).

Os dados de índice de velocidade de emergência (IVE) foram normalizados pela fórmula e em seguida foram submetidos à análise de variância (ANOVA). As médias 
foram comparadas entre si pelo teste de Tukey a 5\% de probabilidade, utilizando o software Assistat, versão 7.7 (Silva \& Azevedo, 2016).

Foi observado que o tratamento com ácido sulfúrico apresentou a maior média de porcentagem de emergência $(\% \mathrm{E})$, com $92 \%( \pm 8,64)$ de germinação. Os demais tratamentos não diferiram estatisticamente entre si, apresentando valores variando entre $53 \%( \pm 14,37)$ e $71 \%( \pm 16,77)$ de germinação (Tabela 1).

Tabela 1. Porcentagem (\%E), índice de velocidade (IVE) e tempo médio de emergência (TME) de sementes de pauferro (Libidibia ferrea) após a aplicação dos tratamentos para superação de dormência.

Table 1. Percentage $(\% \mathrm{E})$, speed index (IVE) and mean time of emergence (TME) of ironwood seeds (Libidibia ferrea) after application of treatments to overcome dormancy.

\begin{tabular}{lccc}
\hline \multicolumn{1}{c}{ Tratamentos } & $\mathbf{\% E}$ & IVE & TME \\
\hline T1 - Controle & $54 \mathrm{~b}( \pm 11,54)$ & $1,31 \mathrm{c}( \pm 0,11)$ & $11,21 \mathrm{a}( \pm 1,83)$ \\
T2 - Ácido sulfúrico & $92 \mathrm{a}( \pm 8,64)$ & $4,50 \mathrm{~b}( \pm 0,28)$ & $6,34 \mathrm{~b}( \pm 0,20)$ \\
T3 - Água por 24 h & $53 \mathrm{~b}( \pm 14,37)$ & $1,22 \mathrm{c}( \pm 0,20)$ & $11,85 \mathrm{a}( \pm 1,30)$ \\
T4 - Água quente & $59 \mathrm{~b}( \pm 11,01)$ & $1,35 \mathrm{c}( \pm 0,21)$ & $12,06 \mathrm{a}( \pm 1,92)$ \\
T5 - Escarificação & $71 \mathrm{ab}( \pm 16,77)$ & $7,67 \mathrm{a}( \pm 0,61)$ & $3,50 \mathrm{~b}( \pm 0,74)$ \\
\hline \multicolumn{1}{c}{ CV (\%) } & 19,43 & 33,94 & 15,23 \\
\hline
\end{tabular}

Médias seguidas por mesma letra na coluna não diferem entre si pelo teste de Tukey a $5 \%$ de probabilidade. $\mathrm{CV}=$ coeficiente de variação.

O tratamento de ácido sulfúrico foi o melhor entre os testados para esta variável, indicando que o tempo de imersão no ácido não afetou o embrião, e foi suficiente para que as sementes pudessem absorver água e retomar os processos metabólicos para que o processo germinativo ocorresse. Os tratamentos água $24 \mathrm{~h}$ e água quente não se mostraram eficazes para a variável avaliada. Possivelmente, o tempo de imersão não foi suficiente para a absorção de água de maneira eficiente para a hidratação do embrião e superação de dormência das sementes. Segundo Marcos Filho (2005), as sementes absorvem água gradativamente. A água vai ocupando espaços secos, enquanto os tecidos já umedecidos vão aumentando o seu teor de água, gerando diferentes gradientes de hidratação no interior das sementes. Ou ainda, pode gerar danos ao embrião, devido à embebição de maneira rápida, quando se faz imersão direta.

O tratamento escarificação apresentou valores intermediários (71\%), não diferindo do tratamento ácido sulfúrico. A utilização de lixa para escarificação pode ser uma alternativa viável para superação de dormência, evitando utilizar reagentes químicos. Porém, deve-se tomar cuidado para não danificar o embrião, fazendo com que essa porcentagem de germinação diminua ou até mesmo ocorra a germinação das sementes, porém resultando em plântulas anormais.

Para os resultados obtidos do índice de velocidade de emergência (IVE), observou-se que as sementes sujeitas à escarificação diferiram dos demais tratamentos, apresentando as maiores médias (Tabela 1). O uso de ácido sulfúrico e escarificação tiveram, em média, resultados $79 \%$ superiores aos demais tratamentos, mostrando que as sementes germinaram mais rápido. Esses resultados mostram a eficiência dos tratamentos utilizados, indicando uma germinação mais rápida e mais homogênea, quando comparados com os demais tratamentos com imersão em água e também o tratamento controle.

Em relação ao tempo médio de germinação (TME), observou-se que os tratamentos que obtiveram as maiores médias, e não diferiram entre si, foram os tratamentos controle (média de 11 dias); água 24 h e água quente, com médias de 12 dias (Tabela 1). Portanto, as sementes que passaram por esses tratamentos levaram mais tempo para germinar, em comparação com os tratamentos escarificação e ácido sulfúrico, que apresentaram médias de 3 e 7 dias para germinarem, respectivamente. A germinação mais lenta observada nos tratamentos controle, água $24 \mathrm{~h}$ e água quente pode ser explicada pela ineficiência dos mesmos, indicando que as sementes ainda apresentavam algum impedimento para iniciar o processo de germinação.

Santana et al. (2011), estudando quebra de dormência de sementes de pau-ferro, observaram que escarificação com lixa $\mathrm{n}^{\circ} 120$ e imersão em água $100{ }^{\circ} \mathrm{C}$ por $10 \mathrm{~s}$ apresentaram as maiores médias para porcentagens de germinação ( $97 \%$ e $88,5 \%$, respectivamente). Tais resultados diferem da presente pesquisa, visto que os tratamentos utilizando imersão em água apresentaram médias menores que $60 \%$ de emergência. Dantas et al. (2015) avaliaram tratamentos pré-germinativos utilizando escarificação mecânica em sementes de $L$. ferrea com lixa $\mathrm{n}^{\circ} 80$, com posterior imersão em água por $24 \mathrm{~h}$, e observaram, em média, $81 \%$ de germinação, enquanto os tratamentos controle e imersão em água por $24 \mathrm{~h}$ apresentaram porcentagem de germinação menor que 50\%. Quando esses autores avaliaram a germinação apenas com a escarificação, a germinação foi baixa, em torno de $57 \%$, enquanto na presente pesquisa este método de superação de dormência apresentou valores médios de $71 \%$. Tais resultados podem ser explicados pela maior absorção de água pelas sementes devido à escarificação. 
Comparando com a presente pesquisa, pode-se observar um comportamento diferente dos resultados para os tratamentos com imersão em água, visto que a \% $\mathrm{E}$ apresentou valores superiores a 50\%. Essa diferença nos valores encontrados pode ter sido influenciada por diferenças na efetividade da escarificação, em função de diferenças na granulometria das lixas ou por um possível dano ocorrido no embrião ou nos cotilédones, estrutura responsável pela reserva energética das sementes, o que pode comprometer o desenvolvimento inicial até que a plântula seja capaz de realizar fotossíntese, tornando-se um indivíduo autótrofo.

Outro fator que também pode influenciar nos baixos resultados da germinação, está relacionado com a perda de vigor das sementes, quando há perda da capacidade de formar uma plântula com parte aérea e raízes bem desenvolvidas durante o crescimento da planta (Oliveira, 2012).

Em relação ao IVE, Negri et al. (2009) observaram um aumento nos tratamentos por meio da escarificação com lixa e com ácido sulfúrico, bem como uma redução significativa no tempo de germinação das sementes. Tais resultados comprovam a eficácia da utilização do ácido sulfúrico e da lixa para superação de dormência de sementes, testados na presente pesquisa. Para Câmara et al. (2008), que avaliaram a germinação do pau-ferro com diferentes tipos de vinagre, o IVE representa uma relação direta entre a velocidade de emergência e o crescimento da planta.

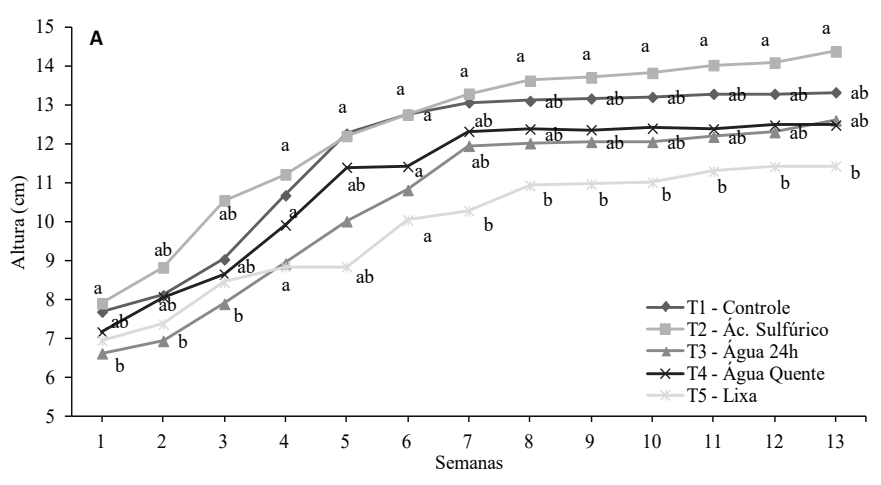

Segundo Taiz et al. (2017) a fase de transição entre a germinação das sementes e o crescimento é o ponto crítico para o estabelecimento, crescimento e desenvolvimento da plântula, visto que é nesse período em que ocorre a maior susceptibilidade à ação de agentes bióticos e abióticos.

Pode-se observar pela Figura 1A que durante todo o período experimental as mudas do tratamento com ácido sulfúrico mantiveram maior crescimento em altura, apresentando média igual a $14 \mathrm{~cm}$ ao final do período estudadoe A escarificação com lixa apresentou o pior resultado para essa variável $(11 \mathrm{~cm})$. O tratamento com ácido sulfúrico apresentou um aumento de 7\% em relação ao tratamento controle e $20 \%$ em relação ao tratamento com lixa, ao final do experimento. Os tratamentos água 24 h e água quente não diferiram dos demais tratamentos avaliados durante todo o período experimental. Tais resultados mostram que a utilização do ácido sulfúrico para quebra de dormência não afetou o crescimento inicial em altura das mudas. Embora os tratamentos controle, água $24 \mathrm{~h}$ e água quente tenha apresentado um menor número de sementes germinadas, observa-se que o crescimento inicial destas não foi afetado. No entanto, as sementes que passaram por escarificação, embora tenham apresentado elevada \%E e IVE e menor TME, a partir da $7^{\mathrm{a}}$ semana de avaliação apresentaram menor incremento em altura.

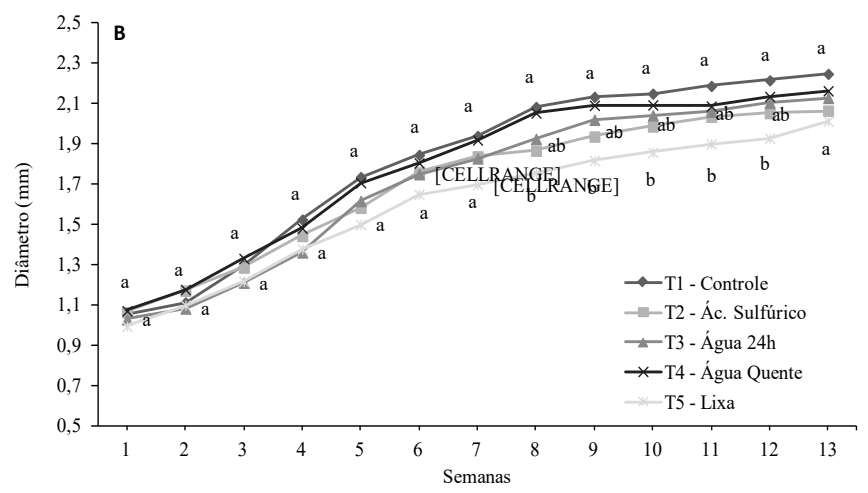

Figura 1. Avaliação da altura (A) e diâmetro do caule (B), das mudas de pau-ferro (Libidibia ferrea). Médias seguidas por mesma letra não diferem entre si pelo teste de Tukey a $5 \%$ de probabilidade.

Figure 1. Evaluation of height (A) and stem diameter (B), of ironwood seedlings (Libidibia ferrea). Means followed by the same letter do not differ by Tukey test at $5 \%$ probability. 
Quando avaliados os valores obtidos pelas medições de diâmetro do caule das mudas (Figura 1B), foi possível observar que inicialmente todas as plântulas apresentavam o mesmo valor médio, independente do tratamento. As diferenças começaram a se manifestar apenas a partir da $8^{\mathrm{a}}$ semana de avaliação, voltando a se igualar estatisticamente na $13^{\mathrm{a}}$ semana. Os tratamentos controle e água quente apresentaram as maiores médias, diferindo dos demais tratamentos, com médias iguais a $2,21 \mathrm{~mm}$ e $2,13 \mathrm{~mm}$ respectivamente, até a $12^{\mathrm{a}}$ semana.
O tratamento lixa diferiu, a partir da $8^{\mathrm{a}}$ semana, dos tratamentos controle e água quente, com média igual a $1,92 \mathrm{~mm}$ na penúltima semana de avaliação.

O número de folhas não foi afetado durante todo o período experimental e, independente do tratamento, observou-se a emissão de novas folhas até a $13^{\mathrm{a}}$ semana de avaliação (Figura 2A).Observou-se que as raízes tiveram maior produção de matéria seca, em relação às folhas e ao caule (Figura 2B).
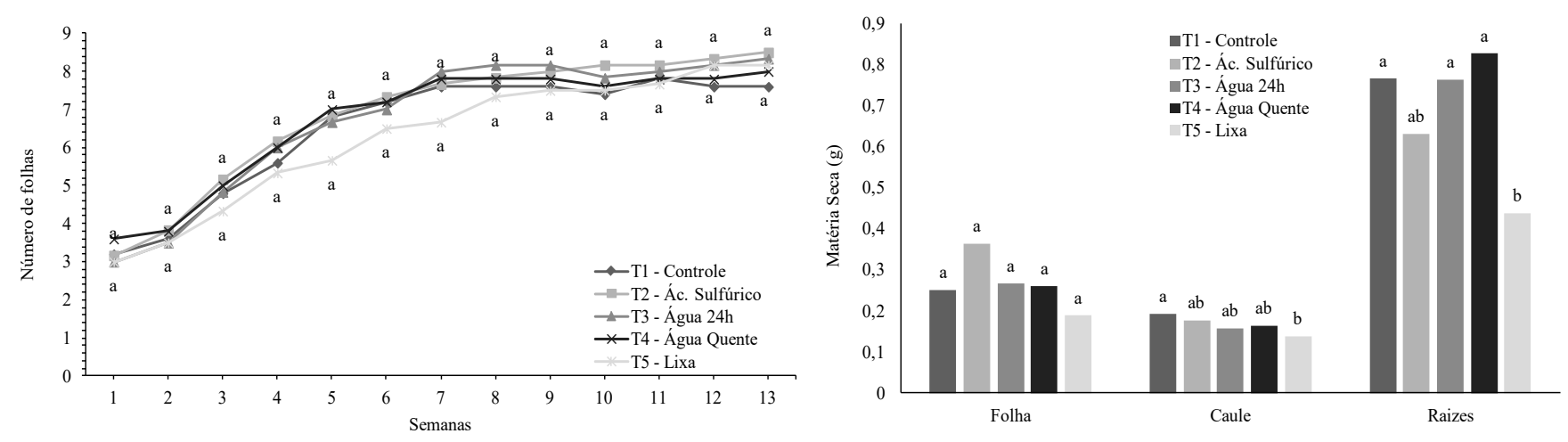

Figura 2. Avaliação do número de folhas (A) e produção de matéria seca (B) das folhas, caule e raízes, das mudas de pau-ferro (Libidibia ferrea). Médias seguidas por mesma letra não diferem entre si pelo teste de Tukey a 5\% de probabilidade.

Figure 2. Evaluation of the number of leaves (A) and dry matter yield (B) of the leaves, stem and roots of ironwood seedlings (Libidibia ferrea). Means followed by the same letter do not differ by Tukey test at 5\% probability.

A produção de MSF não apresentou diferença significativa entre os tratamentos, com médias entre $0,18 \mathrm{~g}$ e $0,36 \mathrm{~g}$. A MSC apresentou valores menores do que os observados na MSF do tratamento utilizando lixa, apresentando a menor média $(0,13 \mathrm{~g})$. Os demais tratamentos não diferiram do tratamento controle.

Em relação à MSR, o tratamento com lixa também diferiu dos demais tratamentos, apresentando a menor média $(0,43 \mathrm{~g})$ e os tratamentos controle, água $24 \mathrm{~h}$ e água quente apresentaram as maiores médias de produção de MSR (0,76 g, 0,76 g, 0,82 g respectivamente), não diferindo estatisticamente entre si. O sistema radicial é um elemento fundamental para estabilidade da planta no substrato, absorvendo água e nutrientes, e também apresentando ligação entre a rizosfera e a parte aérea, e por isso desenvolvem sistemas complexos para fixação e estabelecimento (Taiz et al., 2017). Por isso, as plantas apostam em desenvolvimento radicial no crescimento inicial como forma de garantir a disponibilidade de água e nutrientes para o crescimento, principalmente espécies com ocorrência em regiões áridas e semiáridas, como é o caso do pau-ferro.

Embora o tratamento com lixa tenha apresentado uma boa porcentagem de germinação, assim como uma rápida germinação, seu crescimento é mais lento em relação aos demais tratamentos. Por sua vez, os tratamentos água 24 h e água quente, mesmo apresentando baixa porcentagem de germinação, apresentaram crescimento das raízes melhor que os tratamentos com ácido sulfúrico e lixa. A razão raiz/parte aérea também não apresentou diferenças estatísticas entre os tratamentos analisados, visto que mesmo as folhas e caule apresentando menor produção de matéria seca separadamente, ao serem analisados em conjunto, representando a parte aérea, apresentaram valores equivalentes aos encontrados para as raízes. 


\section{Conclusões}

As sementes de Libidibia ferrea submetidas à imersão em ácido sulfúrico apresentaram maior crescimento inicial, diferentemente do que foi visto nos tratamentos controle, imersão em água por 24 h, imersão em água quente, ou escarificação. Embora o tratamento de escarificação tenha apresentado porcentagem de germinação favorável, o crescimento inicial foi afetado negativamente.

\section{Referências}

Benincasa, M. M. P. Análise de crescimento de plantas. 2. ed. Jaboticabal: FUNEP, 2003. 41 p.

Câmara, F. A. A. et al. Biometria de frutos e sementes e superação de dormência de jucá (Caesalpinea ferrea Mart. ex. Tul. (Legumisosae - Caesalpinoideae). Revista Caatinga, v. 21, n. 4, p. 172-1778, 2008.

Carvalho, N. M. \& Nakagawa, J. Sementes: ciência, tecnologia e produção. 4. ed. Jaboticabal: Funep, 2000. 588 p.

Dantas, J. M. et al. Quebra de dormência em sementes de Libidibia ferrea Martius. Blucher Chemistry Proceedings, v. 3, n. 1, p. 5662, 2015.

Galdino, G. et al. Descrição morfológica da plântula e diásporos de Caesalpinia ferrea Mart. Revista Brasileira de Biociências, v. 5, supl. 2, p. 747-749, 2007.

Labouriau, L. G. A germinação das sementes. Lima: SecretariaGeral da OEA, 1983. 174 p. (OEA-Serie de Biologia. Monografia, 24).
Lima, B. G. Caatinga: espécies lenhosas e herbáceas. Mossoró: EdUfersa, 2012. 316 p.

Lorenzi, H. Árvores brasileiras: manual de identificação e cultivo de plantas arbóreas nativas do Brasil. Nova Odessa: Plantarum, 1992. $146 \mathrm{p}$.

Maguire, J. D. Speed of germination and selection and evaluation for seedling emergence and vigour. Crop Science, v. 2, n. 2, p. 176-177, 1962.

Maia, G. N. Caatinga: árvores e arbustos e suas utilidades. 2. ed. Fortaleza: Printcolor, 2012. 413 p.

Marcos Filhos, J. Fisiologia de sementes de plantas cultivadas. Piracicaba: Fealq, 2005. 495 p.

Negri, L. C. G. et al. Quebra de dormência de sementes de espécies arbóreas. Revista em Agronegócios e Meio Ambiente, v. 2, n. 3, p. 487-500, 2009.

Oliveira, O. S. Tecnologia de sementes florestais: espécies nativas. Curitiba: Ed. da UFPR, 2012. 404 p.

Santana, J. A. S. et al. Tecnologias de baixo custo para superação de dormência em sementes de Caesalpinia ferrea var. ferrea Mart. ex. Tul. (pau-ferro). Revista Verde, v. 6, n. 1, p. 225-229, 2011.

Silva, M. L. et al. Desenvolvimento inicial de plântula de Caesalpinea ferrea Mart. ex Tull. em função de diferentes substratos. Cadernos de Agroecologia, v. 6, n. 2, 2011.

Silva, F. A. S. \& Azevedo, C. A. V. The assistat software version 7.7 and its use in the analysis of experimental data. African Journal of Agricultural Research, v. 11, n. 39, p. 3733-3740, 2016.

Taiz, L. et al. Fisiologia e desenvolvimento vegetal. 6. ed. Porto Alegre: Artmed, 2017. 858 p. 